\title{
Animal models of ventilator-associated pneumonia
}

\author{
C.M. Luna*, O. Sibila\#, C. Agusti ${ }^{\top}$ and A. Torres
}

ABSTRACT: Animal models are an essential step between "in vitro" testing and clinical studies. Different animal models have been useful for the study of pathophysiology, diagnosis and therapy in ventilator-associated pneumonia (VAP).

Aspiration has been studied in dog and cat models and bacteriological diagnosis has been evaluated in baboons. Pigs have been used for studying either spontaneous or induced VAP. Intubated piglets in prone position were administered analgesia and muscle paralysis was induced, and the intubated piglets underwent mechanical ventilation for several days. In this model, spontaneous VAP due to common bacterial pig colonisation develops within a few days. Pneumonia can also be induced by inoculating high concentrations of microorganisms (Pseudomonas aeruginosa and methicillin-resistant Staphylococcus aureus).

Different clinical, physiological, microbiological and pathological parameters of infection have been studied in this model. In addition, administration of antibiotics and inflammatory modulators and their consequences in microbiological eradication and local and systemic inflammation have been evaluated with interesting translational results.

Although bronchial inoculation of healthy subjects does not resemble the common pathophysiological mechanisms, the experimental model of ventilator-associated pneumonia induced by the inoculation of high concentrations of microorganisms in mechanically ventilated piglets is useful for the study of the local and systemic responses of lung infection and for the determination of potential measures of prevention or therapeutic modulation.

KEYWORDS: Animal model, antimicrobial therapy, inflammatory markers, ventilator-associated pneumonia

V entilator-associated pneumonia (VAP) is defined as pneumonia in patients intubated and/or receiving invasive mechanical ventilation for $>48 \mathrm{~h}$. Rates of pneumonia are increased 6- to 21-fold for intubated patients and show a further rise with the duration of mechanical ventilation. In the intensive care unit (ICU), the risk of mortality appears to be 2- to 10-fold higher in patients with nosocomial pneumonia [1]. The diagnosis of VAP requires a new radiographic infiltrate and, in addition, two out of the following conditions: fever or hypothermia; leukocytosis or leukopenia; and/or purulent tracheobronchial secretions. VAP is a frequent and severe infection in the ICU setting with an incidence of $9-20 \%$ among mechanically ventilated patients $[2,3]$ and a mortality rate of $20-80 \%$ [4]. Many aspects regarding the pathophysiology, diagnosis and therapy of VAP remain unsolved.

Animal models are an essential step between in vitro testing and clinical studies, and are necessary for the understanding of pathophysiology, pharmacology and efficacy of therapy. An animal model provides a unique opportunity to study some of the incompletely understood mechanisms involved in VAP, such as the role of inflammation, the dynamics of bacterial colonisation and/or

Previous articles in this series: No. 1: 0eckler RA, Hubmayr RD. Ventilator-associated lung injury: a search for better therapeutic targets. Eur Respir $J$ 2007; 30: 1216-1226. No. 2: Chung KF, Adcock IM. Multifaceted mechanisms in COPD: inflammation, immunity, and tissue repair and destruction. Eur Respir J 2008; 31: 1334-1356. No. 3: Meurs H, Gosens R, Zaagsma J. Airway hyperresponsiveness in asthma: lessons from in vitro model systems and animal models. Eur Respir J 2008; 32: 487-502.

AFFILIATIONS

*Pulmonary Diseases Division, Hospital de Clínicas, Universidad de Buenos Aires, Buenos Aires, Argentina.

${ }^{\text {\#} S e r v e i ~ d e ~ P n e u m o l o g i a, ~ H o s p i t a l ~}$ Son Dureta. Fundació CaubetCimera, Ciberes, Palma de Mallorca, and

'Servei de Pneumologia, Institut Clínic del Tòrax, Hospital Clínic, IDIBAPS, Ciberes, Barcelona, Spain.

CORRESPONDENCE

C.M. Luna

Acevedo 1070

Banfield

1828

Buenos Aires

Argentina

Fax: 541142026068

E-mail: cymluna@fmed.uba.ar

Received:

March 262008

Accepted after revision:

June 302008

STATEMENT OF INTEREST

Statements of interest for C.M. Luna and $\mathrm{A}$. Torres can be found at www.erj.ersjournals.com/misc/ statements.shtml 
infection, and the response to antimicrobial therapy. Some advantages of an animal model of VAP are based on the accurate control of significant variables, such as the precise timing of the infectious challenge. This allows better control of different phenomena and their relationship with the time elapsed from the onset of the infectious insult, minimising the confounding impact of spontaneous airway colonisation. Additionally, the effect of antimicrobial therapy on cultures can be better controlled, and pharmacokinetic and pharmacodynamic studies can be accurately performed.

This article summarises the published experience in animal models, particularly the piglet model, of VAP; the dynamics of spontaneous and artificially induced lung infection; the value of different culture methods in lung infections; the pathophysiology of inflammation; and the pharmacokinetics and pharmacodynamics of antimicrobial agents.

\section{ANIMAL MODELS OF VAP}

There have been few studies of experimental aspiration pneumonia, and these were mainly carried out in the 1970s using cats and dogs to study the pathophysiology of lung injury [5]. In addition, TILSON et al. [6] have studied the quantitative bacteriology and pathology of the lung in experimental Pseudomonas aeruginosa pneumonia treated with positive end-expiratory pressure (PEEP) and MOSER et al. [7] have used a canine model of pneumonia to compare the yield of different diagnostic procedures in experimentally induced Streptococcus pneumoniae pneumonia. However, the first attempts to use an animal model for the study of different aspects of nosocomial pneumonia following mechanical ventilation were the studies carried out by JOHANSON and COworkers [8-10] in the 1980s, which used a baboon model to study the bacteriological diagnosis of pneumonia. In the studies by JOHANSON and co-workers [8-10], cultures of tracheal secretions, bronchoalveolar lavage (BAL), protected specimen brushes (PSB) and direct lung aspirates were compared with cultures of lung homogenates and with histological findings. The efficacy of antimicrobial agents applied topically in the oropharynx and trachea with and without intravenous antibiotics in preventing bacterial pneumonias was also studied in 35 baboons after 7-10 days of intubation and mechanical ventilation.

MARQUETTE et al. [11] developed a model of experimental pneumonia in mechanically ventilated subjects using $22 \pm 2 \mathrm{~kg}$ Landrace-White piglets. It was found that piglets mechanically ventilated for 4 days with experimentally created tracheal stenosis consistently developed spontaneous pneumonia and, therefore, the authors decided to conduct a study comparing the histological and bacteriological findings in previously healthy pigs infected with bacterial pneumonia while free of antibiotic therapy. Lung pathology was evaluated according to a pathological score described elsewhere (table 1) [13]. Characterisation of this piglet model has been extensively described elsewhere [12].

In order to achieve adequate general anaesthesia, and analgesia and muscle paralysis to allow the animals to be maintained on mechanical ventilation for several days, MARQUETTE et al. [11] developed a well-tolerated drug combination of midazolam, fentanyl and pancuronium bromide. They also designed an "ideal" regimen of fluid and electrolyte supply to obtain a stable haemodynamic status and satisfactory electrolyte balance. Other problems, such as catheter insertion for haemodynamic and oxygenation monitoring, arterial and venous blood sampling, and vesical catheters, were also solved.

Piglets were ventilated in the prone position, as with sheep or cows, because mechanical ventilation in the supine position results in lung atelectasis with severe ventilation/perfusion mismatch within a few hours. Ventilation parameters were adjusted to maintain arterial carbon dioxide tension 35$45 \mathrm{mmHg}(4.7-6.0 \mathrm{kPa})$ and arterial oxygen saturation $90 \%$ throughout the study period. Endotracheal suctioning was routinely performed for removal of excess secretions. In the original description of this model, parenteral feeding, fluids and electrolytes were provided through continuous infusion of Ringer's lactate $\left(125 \mathrm{~mL} \cdot \mathrm{h}^{-1}\right)$ and $10 \%$ glucose $\left(40 \mathrm{~mL} \cdot \mathrm{h}^{-1}\right)$ [12]; however, other approaches have been used by other investigators [14]. The piglets remained under mechanical ventilation for 3-4 days, and were then sacrificed by an infusion of $\mathrm{KCl}$.

Spontaneous pneumonia due to common airway colonising microorganisms in pigs is nearly a constant feature after several days under mechanical ventilation (Pasteurella multocida and Streptococcus suis are commonly present, but Klebsiella oxitoca, P. aeruginosa, Staphylococcus epidermidis and S. aureus can also be isolated; table 2) [15]. Pneumonia may be also induced by the inoculation of solutions with a high concentration of pathogens $\left(10^{6}\right.$ to $10^{8}$ colony-forming units (CFU) $\left.\cdot \mathrm{mL}^{-1}\right)$. K. oxitoca, Escherichia coli, P. aeruginosa, S. aureus and Group B streptococci have been used for this in different studies $[12,16-$ 21]. The use of antimicrobials as part of the research protocol may either have a therapeutic effect, sterilising the lungs from pathogenic microorganisms, or a prophylactic effect against the development of infection by colonisers or inoculated microorganisms $[12,14]$.

Routine and special procedures included: daily biochemistry laboratory determinations and blood gas analysis; strict control of common physiological variables (body temperature and haemodynamics); ventilatory monitoring; basal and post mortem cultures (blood, BAL and lung tissue); blood and BAL measurement of inflammatory markers (cytokines and acute phase reactants); pharmacokinetics and pharmacodynamics of antimicrobials and post mortem pathology of lung and other organs.

\section{DYNAMICS OF SPONTANEOUS LUNG INFECTION IN MECHANICALLY VENTILATED ANIMALS}

Piglets subjected to prolonged mechanical ventilation and/or experimental bronchial stenosis rapidly develop endogenous pneumonia, predominantly due to $P$. multocida or S. suis [22]. Parenchymal bacterial burden is unevenly distributed within the lungs and even within the lung segments, and there is no clear-cut threshold for quantitative cultures that allows discrimination of the presence or absence of pneumonia. The administration of ceftriaxone reduces the incidence of histologically proven pneumonia and the bacterial burden of pneumonia tissue. Nearly all piglets that received antibiotics, but less than half of those that received ceftriaxone, developed histologically proven pneumonia $(\mathrm{p}<0.05)$. Pneumonia was present in $54 \%$ of 


\begin{tabular}{lll}
\hline TABLE 1 & Pathological grading of pneumonia & \\
\hline Grade & Synonym & Description \\
\hline $\mathbf{0}$ & No pneumonia & Absence of lesions \\
$\mathbf{1}$ & Mucus plugging & Purulent mucus plugging in peripheral airway \\
$\mathbf{2}$ & Bronchiolitis & Polymorphonuclear leukocytes localised within the lumen and bronchiolar wall alterations \\
$\mathbf{3}$ & Pneumonia & Focal polymorphonuclear leukocytes, fibrin and few erythrocytes in the alveolar lumen \\
$\mathbf{4}$ & Confluent pneumonia & Confluent pneumonia lesions \\
$\mathbf{5}$ & Abscessed pneumonia & Pneumonia coexisting with parenchymal necrosis \\
\hline \#: as described by MARQUETTE et al. [12]. &
\end{tabular}

the dependent segments and in only $25 \%$ of the nondependent lung segments $(p<0.05)$. In $75 \%$ of the cases, pneumonia involved both lungs [15].

WERMET et al. [15] found that, after 4 days of mechanical ventilation in piglets with histologically proven pneumonia, the mean bacterial count was $7.8 \times 10^{2} \pm 7.1 \times 10^{2} \mathrm{CFU} \cdot \mathrm{g}^{-1}$ in a group treated with ceftriaxone, but it was $4.5 \times 10^{5} \pm 2 \times 10^{5} \mathrm{CFU} \cdot \mathrm{g}^{-1}$ in those receiving no antibiotics $(p<0.01)$ [15]. The histological scores were significantly higher in the untreated animals $(2.04 \pm 1.62$ versus $0.83 \pm 1.24 ; \mathrm{p}<0.001)$. There was a not straightforward correlation between the total number of bacteria grown in pulmonary biopsy specimens and the corresponding histological grades $(p<0.01)$; however, no clear-cut bacteriological cut-off could be defined for the differentiation of presence or absence of pneumonia by histopathological criteria [12].

\section{THE VALUE OF DIFFERENT CULTURE METHODS IN THE DIAGNOSIS OF PNEUMONIA}

WERMERT et al. [15] demonstrated that the sensitivities and specificities of different quantitative culture methods in recognising the histological presence or absence of spontaneous pneumonia in piglets not receiving antibiotics were $74 \%$ and $36 \% \geqslant 10^{3} \mathrm{CFU} \cdot \mathrm{mL}^{-1}$ for PSB, $82 \%$ and $33 \% \geqslant 10^{4} \mathrm{CFU} \cdot \mathrm{mL}^{-1}$ for BAL and $100 \%$ and $0 \% \geqslant 10^{5} \mathrm{CFU} \cdot \mathrm{mL}^{-1}$ for endotracheal

\begin{tabular}{|c|c|c|}
\hline Microorganism & $\begin{array}{c}\text { Isolates } \\
\geqslant 10^{4} \mathrm{CFU} \cdot \mathrm{g}^{-1}\end{array}$ & $\begin{array}{c}\text { Isolates } \\
<10^{4} \mathrm{CFU} \cdot \mathrm{g}^{-1}\end{array}$ \\
\hline Pasteurella multocida & 40 & 12 \\
\hline Klebsiella oxytoca & 2 & \\
\hline Citrobacter freundii & & 2 \\
\hline Moraxella catarrhalis & & 1 \\
\hline Pseudomonas aeruginosa & & 1 \\
\hline Streptococcus suis & 20 & 5 \\
\hline Streptococcus bovis & 13 & 2 \\
\hline Staphylococcus epidermidis & 3 & 2 \\
\hline Staphylococcus aureus & 3 & 4 \\
\hline Bacillus sp. & & 1 \\
\hline
\end{tabular}

CFU: colony-forming unit. Modified from [12] with permission from the publisher. aspirate. The sensitivity of BAL or PSB was always lower when calculated by taking the whole lung histology as a reference diagnosis than when considering the particular sampled segment histology. This may be because pneumonia is not homogeneously distributed throughout the lungs and, therefore, the segments studied by PSB or BAL in a certain number of animals with pneumonia were free of pneumonia.

Conversely, in piglets receiving antibiotics, the sensitivities and specificities of PSB, BAL and endotracheal aspirate, were $0 \%$ and $100 \%, 50 \%$ and $93 \%$, and $50 \%$ and $80 \%$ [15].

In a model of pneumonia induced by the inoculation of microorganisms, LUNA et al. [14] observed that quantitative BAL cultures performed after 3 days of challenge with $P$. aeruginosa from all piglets not receiving antibiotics yielded $\geqslant 10^{4} \mathrm{CFU} \cdot \mathrm{mL}^{-1}$ of $P$. aeruginosa as the only microorganism, thereby confirming the high diagnostic accuracy and pathogen identification of BAL culture for pneumonia in subjects not receiving antimicrobials. Conversely, the accuracy of BAL culture was reduced in piglets receiving antimicrobials. In the animal model, this fact confirms the limited utility of BAL culture for evaluating the presence of infection and the appropriateness of antimicrobial therapy in subjects receiving prior antibiotics. Although pneumonia was present in all the piglets, bacterial growth $\geqslant 10^{4} \mathrm{CFU} \cdot \mathrm{mL}^{-1}$ in the BAL culture was obtained in $100 \%$ of those in the no antibiotics group, but only in $22 \%$ of those receiving antimicrobials. Appropriate or inappropriate antimicrobial therapy was associated with negative BAL and lung tissue culture findings in pathologically confirmed VAP ( $p<0.027$; fig. 1) [14]. However, one of the most important contributions of the animal model studies to the diagnosis of VAP was the demonstration that, although there is a clear association between pathology score and bacterial load in culture lung tissue homogenates, there is large overlap; as a consequence, bronchiolitis may be associated with high, and lung abscess with low, bacterial burden (fig. 2) [22]. Conversely, the multifocal presentation of experimentally induced piglet pneumonia, particularly in the dependent regions of the lung, a main finding of animal studies, resembles the pathological findings observed in VAP $[12,15]$.

\section{PATHOPHYSIOLOGY OF INFLAMMATION IN EXPERIMENTAL VAP}

Over the last years, compelling evidence has demonstrated the importance of host inflammatory response in the evolution of bacterial infections. It is well known that the introduction of pathogens to the alveolar space creates a complex inflammatory 


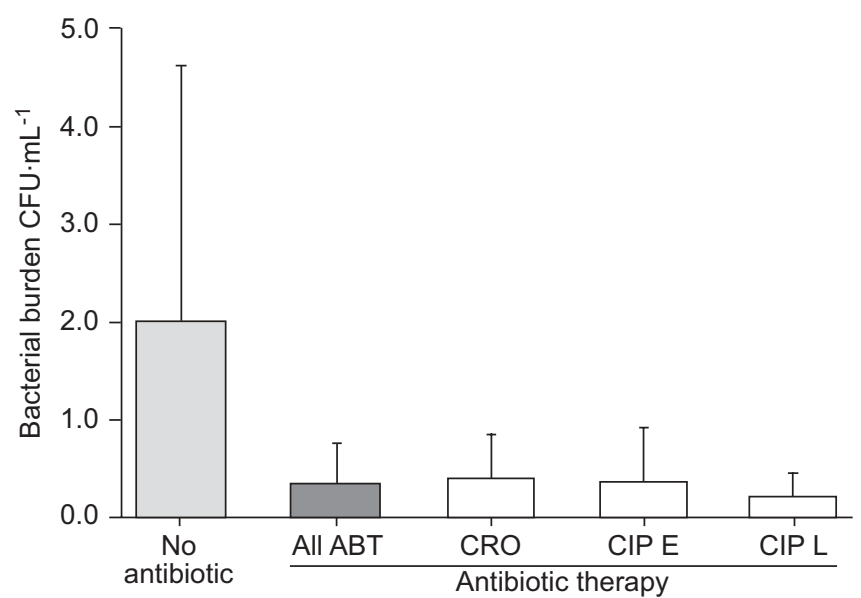

FIGURE 1. Differences in the bacterial burden observed in lung tissue culture between piglets not receiving antibiotic therapy (ABT) versus those receiving either inappropriate ABT (ceftriaxone (CIP)) or appropriate ABT (ciprofloxacin (CRO)). The difference between the colony-forming units (CFU) per millilitre in the lung tissue of piglets not receiving $A B T$ versus those receiving either $A B T$ was significant $(p=0.007)$. E: early; L: late. Reproduced from [14] with permission from the publisher.

response with the interaction of several defence mechanisms and the production of different inflammatory mediators and acute phase proteins. This inflammatory response aims to control the progression of infection and to destroy microorganisms, and consists of several proinflammatory (tumour necrosis factor (TNF)- $\alpha$, interleukin (IL)-1 $\beta$, IL- 6 and IL-8) and anti-inflammatory (IL-10, IL-1RA, sTNFrp55 and sTNFrp75) cytokines. Cytokines promote migration of defence cells, such as neutrophils, lymphocytes and platelets, through the circulatory system to inflammatory sites [23]. All this process is beneficial, as long as it is limited to the control of local infection. If this reaction is over proportioned, several systemic consequences negatively influence the clinical evolution of the infection [24]. This excessive inflammatory response is associated with the release of inflammatory mediators that can be detected in serum or BAL, and have been shown to have diagnostic and prognostic value. Different studies in severe pneumonia have shown increased levels of different inflammatory cytokines both in the lung and in serum $[25,26]$, and recent publications have demonstrated that an increased inflammatory response is a strong predictor of nonresponse to treatment and mortality in severe community-acquired pneumonia [27]and VAP [28].

In clinical practice, different factors, such as use of antibiotics or the presence of comorbidities, may influence the local and systemic inflammatory response, although the precise role of these factors is difficult to accurately assess in humans. Animal models could help to clarify this issue.

Recent studies in experimental VAP induced by $P$. aeruginosa have evaluated the associated local and systemic inflammatory response. SIBILA et al. [29] studied piglets ventilated for 4 days, and found an increase in different proinflammatory cytokines in both BAL and in serum. In BAL, all the cytokines evaluated (IL-6, IL-1 $\beta$, IL- 8 and TNF- $\alpha$ ) showed a marked increase $96 \mathrm{~h}$ after the induction of the pneumonia and, in serum, an increase

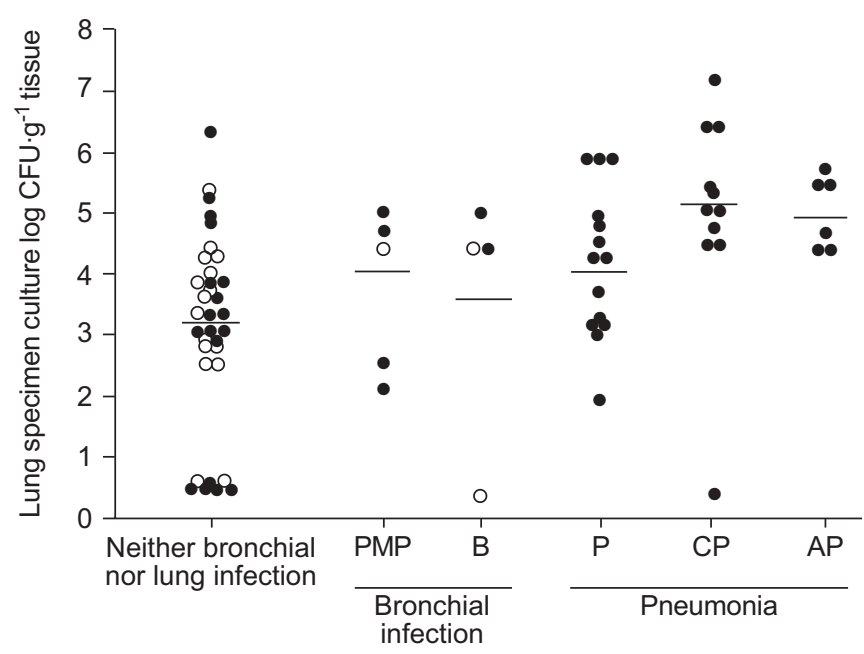

FIGURE 2. Relationship between the number of colony-forming units (CFU) grown in lung culture and their corresponding histological grades in 78 lung specimens. histological evidence of pneumonia; $\bigcirc$ : values in animals with no specimen with histological evidence of pneumonia. PMP: purulent mucous plugging; $B$ : bronchiolitis; P: pneumonia; CP: confluent pneumonia; AP: abscessed pneumonia Horizontal lines, geometrical mean of values. Modified from [22] with permission from the publisher.

in IL-6 was observed during the $96 \mathrm{~h}$ of the study, with a peak value $48 \mathrm{~h}$ after the inoculation of $P$. aeruginosa (fig. 3). The lung inflammatory response was higher than the systemic inflammatory response, suggesting that the production of cytokines is initially compartmentalised. All these findings were associated with pneumonia lesions in the histopathological analysis performed at the end of the study [29].

In another study with VAP induced by $P$. aeruginosa in ventilated piglets with different antibiotic treatments, LuNA et al. [14] found that piglets that received antibiotic treatment showed a lower local and systemic inflammatory response at the end of the study $(72 \mathrm{~h})$ compared with piglets that had not received antibiotic treatment, suggesting an anti-inflammatory effect of antibiotic treatment. In the study by LuNA et al. [14], an increase in the different cytokines evaluated (IL-6, IL-10 and TNF- $\alpha$ ) was mainly detected in BAL but also in serum, and all these findings were also associated with pneumonia lesions in the histopathological analysis.

The pioneer piglet studies have been made with outdated ventilator settings now known to produce iatrogenic ventilator-induced lung injury (volume controlled, high tidal volume). The older studies used a tidal volume of $15 \mathrm{~mL} \cdot \mathrm{kg}^{-1}$. During past years, more recent studies have used $\sim 10 \mathrm{~mL} \cdot \mathrm{kg}^{-1}$ $[16,18,29,30,31]$; lower tidal volumes produce severe hypoventilation and respiratory acidosis. This should be clearly recognised as a main limitation of these otherwise landmark studies.

In summary, the experimental model of VAP induced by the inoculation of high concentrations of $P$. aeruginosa in mechanically ventilated piglets has proven to be useful for the study of the associated inflammatory response. The study of different local and systemic proinflammatory cytokines showed an 

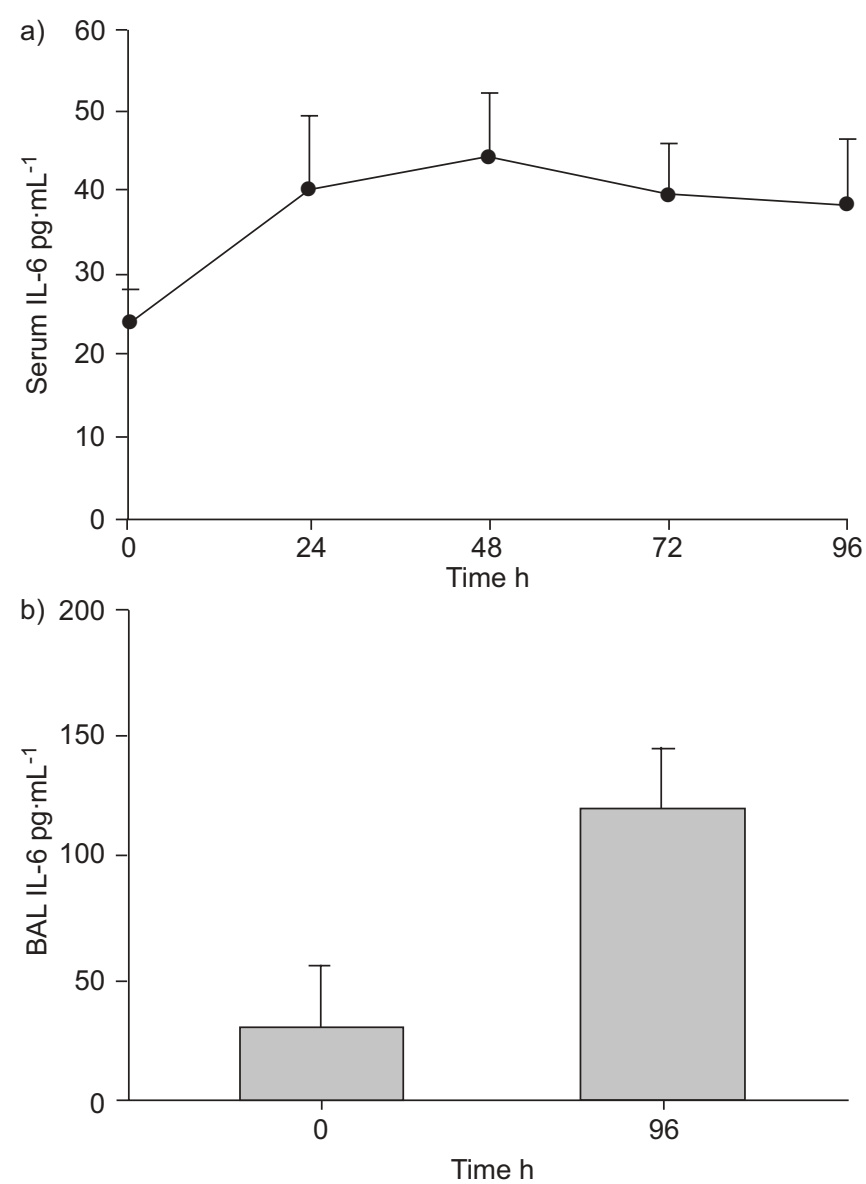

FIGURE 3. Sequential bronchoalveolar lavage (BAL; at 0 and $96 \mathrm{~h}$ ) and serum (at 0, 24, 48, 72 and $96 \mathrm{~h}$ ) interleukin (IL)-6 determinations during the $96 \mathrm{~h}$ following ventilator-associated pneumonia induction. Modified from [30] with permission from the publisher.

increase in the inflammatory mediators (mainly IL-6) after bacterial inoculation that was more marked in BAL than in serum, suggesting that the inflammatory response is mainly compartmentalised.

\section{PHARMACOKINETICS AND PHARMACODYNAMICS OF ANTIMICROBIALS IN EXPERIMENTAL VAP}

Tissue concentration at the site of infection is the main determinant of bactericidal efficiency whereas toxicity depends on trough plasma concentrations [32, 33]. Bacterial eradication may depend on the amount of time antibiotics, such as $\beta$-lactams and quinolones, are above the minimal inhibitory concentration (time dependent); or on the peak concentration achieved (concentration dependent), such as in aminoglycosides. Pharmacokinetic and pharmacodynamic studies can be used to develop dosing strategies for patients as well as to determine clinically relevant doses and dosing strategies in clinical trials [34].

Because of methodological limitations regarding tissue sampling in humans, an animal model is required in order to assess the quantitative deposition in the whole lung parenchyma of intravenously administered and, especially, inhaled antimicobials. Intravenous administration of aminoglycosides and polymyxin achieve low levels in lung tissue [35-39] because plasma levels are kept deliberately low to avoid toxicity. Aerosol administration provides the theoretical advantage of high concentrations of antibiotics at the site of infection together with a low systemic absorption resulting in reduced renal toxicity. GOLDSTEIN et al. [18] studied the lung deposition of amikacin during E. coli experimental pneumonia in ventilated piglets and found that the deposition of amikacin in infected lung parenchyma and the efficiency of bacterial killing were greater after nebulisation than after i.v. administration. Similarly, TONNELLIER et al. [40] observed that nebulisation of ceftazidime induced a several fold increase in lung tissue concentrations as compared with i.v. administration during $P$. aeruginosa experimental pneumonia. A murine model has been used in the past for evaluation of the activity of dalfopristin-quinupristin in experimental S. pneumoniae and $S$. aureus lung infection. Recently, BRUNO et al. [16] described their experience with experimental pneumonia induced by methicillinresistant $S$. aureus, and measured pharmacokinetic and pharmacodynamic parameters of anti-staphylococcal antimicrobials in the piglet model.

\section{HOW TO TRANSLATE THE MODEL TO CLINICAL PRACTICE}

There are several issues to be taken into account in this animal model of VAP before translating results to clinical practice. First, this is an experimental model, in which animals are ventilated and then pneumonia is caused by bronchial instillation. This is not the common pathophysiological mechanism of VAP, in which colonisation and microaspiration to the lower airways are the main steps. Secondly, animals are apparently healthy and do not have comorbidities, which critically ill patients under mechanical ventilation so frequently have and which has a key role in the evolution of patients.

In contrast, there are also clear advantages of this animal model. This is a pure model of pneumonia without the interference of drugs, comorbidities and external factors, and the animals can be maintained for $>3$ days on mechanical ventilation, which represents enough time to see changes due to interventions. Having said that, this experimental model of ventilator-associated pneumonia is potentially useful for the study of: 1) the lung and systemic inflammatory response caused by pneumonia and its potential therapeutic modulation; 2) different diagnostic sampling methods with the advantage of having the gold standard of microbiology and histopathology of lung samples; 3) pharmacokinetic/pharmacodynamic relationships and the microbiological and clinical efficacy of antibiotics; and 4) how pneumonia affects the different patterns and modes of mechanical ventilation. In animals without the bronchial inoculation of high concentrations of pathogens, the model can be useful for the study of preventive measures in ventilator-associated pneumonia.

\section{REFERENCES}

1 Craven DE, Kunches LM, Kilinsky V, Lichtenberg DA, Make BJ, McCabe WR. Risk factors for pneumonia and fatality in patients receiving continuous mechanical ventilation. Am Rev Respir Dis 1986; 133: 792-796. 
2 Vincent JL, Bihari DJ, Suter PM, et al. The prevalence of nosocomial infection in intensive care units in Europe. Results of the European Prevalence of Infection in Intensive Care (EPIC) Study. EPIC International Advisory Committee. JAMA 1995; 274: 639-644.

3 George DL, Falk PS, Wunderink RG, et al. Epidemiology of ventilator-acquired pneumonia based on protected bronchoscopic sampling. Am J Respir Crit Care Med 1998; 158: 1839-1847.

4 American Thoracic Society, Infectious Diseases Society of America. Guidelines for the management of adults with hospital-acquired, ventilator-associated and healthcareassociated pneumonia. Am J Respir Crit Care Med 2005; 171: 388-416.

5 Brandt B, Doyle B, Weintraub H, Harrison H. Pulmonary artery pressure and lung water during extracorporeal circulation in experimental pulmonary insufficiency. Ann Thorac Surg 1975; 20: 308-315.

6 Tilson MD, Bunke MC, Smith GJ, et al. Quantitative bacteriology and pathology of the lung in experimental Pseudomonas pneumonia treated with positive endexpiratory pressure (PEEP). Surgery 1977; 82: 133-140.

7 Moser KM, Maurer J, Jassy L, et al. Sensitivity, specificity, and risk of diagnostic procedures in a canine model of Streptococcus pneumoniae pneumonia. Am Rev Respir Dis 1982; 125: 436-442.

8 Campbell GD, Coalson JJ, Johanson WG Jr. The effect of bacterial superinfection on lung function after diffuse alveolar damage. Am Rev Respir Dis 1984; 129: 974-978.

9 Johanson WG Jr, Seidenfeld JJ, Gomez P, de los Santos R, Coalson JJ. Bacteriologic diagnosis of nosocomial pneumonia following prolonged mechanical ventilation. Am Rev Respir Dis 1988; 137: 259-264.

10 Johanson WG Jr, Seidenfeld JJ, de los Santos R, Coalson JJ, Gomez P. Prevention of nosocomial pneumonia using topical and parenteral antimicrobial agents. Am Rev Respir Dis 1988; 137: 265-272.

11 Marquette $\mathrm{CH}$, Mensier E, Copin MC, et al. Experimental models of tracheobronchial stenoses: a useful tool for evaluating airway stents. Ann Thorac Surg 1995; 60: 651-656.

12 Marquette $\mathrm{CH}$, Wermert $\mathrm{D}$, Wallet $\mathrm{F}$, Copin $\mathrm{MC}$, Tonnel AB. Characterization of an animal model of ventilator-acquired pneumonia. Chest 1999; 115: 200-209.

13 Rouby JJ, Martin De Lassale E, Poete P, et al. Nosocomial bronchopneumonia in the critically ill. Histologic and bacteriologic aspects. Am Rev Respir Dis 1992; 146: 1059-1066.

14 Luna CM, Baquero S, Gando S, et al. Experimental severe Pseudomonas aeruginosa pneumonia and antibiotic therapy in piglets receiving mechanical ventilation. Chest 2007; 132: 523-531.

15 Wermert D, Marquette CH, Copin MC, et al. Influence of pulmonary bacteriology and histology on the yield of diagnostic procedures in ventilator-acquired pneumonia. Am J Respir Crit Care Med 1998; 158: 139-147.

16 Bruno D, Luna CM, Garcia Morato J, et al. Linezolid (LZD) versus vancomycin (VAN) and teicoplanin (TEI) for severe methicillin-resistant Staphylococcus aureus (MRSA) pneumonia in an animal model. Program and abstracts of ATS 2008. International Conference of the American Thoracic Society. Am J Respir Crit Care Med 2008; 177: A287.
17 Elman M, Goldstein I, Marquette $\mathrm{CH}$, et al. Influence of lung aeration on pulmonary concentrations of nebulized and intravenous amikacin in ventilated piglets with severe bronchopneumonia. Anesthesiology 2002; 97: 199-206.

18 Goldstein I, Wallet F, Nicolas-Robin A, Ferrari F, Marquette $\mathrm{CH}$, Rouby JJ. Lung deposition and efficiency of nebulized amikacin during Escherichia coli pneumonia in ventilated piglets. Am J Respir Crit Care Med 2002; 166: 1375-1381.

19 Goldstein I, Bughalo MT, Marquette $\mathrm{CH}$, et al. Mechanical ventilation-induced air-space enlargement during experimental pneumonia in piglets. Am J Respir Crit Care Med 2001; 163: 958-964.

20 Rios Vieira SR, Goldstein I, Lenaour G, et al. Experimental ventilator-associated pneumonia: distribution of lung infection and consequences for lung aeration. Braz J Infect Dis 2003; 7: 216-223.

21 van Kaam AHLC, Lutter R, Lacmann RA, et al. Effect of ventilation strategy and surfactant on inflammation in experimental pneumonia. Eur Respir J 2005; 26: 112-117.

22 Marquette $\mathrm{CH}$, Copin MC, Wallet F, et al. Relationship between microbiologic and histologic features in bacterial pneumonia. Am J Respir Crit Care Med 1996; 154: 1784-1787.

23 Sibille Y, Reynolds HY. Macrophages and polymorphonuclear neutrophils in lung defense and injury. Am Rev Respir Dis 1990; 141: 471-501.

24 Nelson S, Bagby GJ, Bainton BG, Wilson LA, Thompson JJ, Summer WR. Compartmentalization of intraalveolar and systemic lipopolysaccharide-induced tumour necrosis factor and the pulmonary inflammatory response. J Infect Dis 1989; 159: 189-194.

25 Montón C, Torres A, El-Ebiary M, Filella X, Xaubet A, de la Bellacasa JP. Cytokine expression in severe pneumonia: a bronchoalveolar lavage study. Crit Care Med 1999;27: 1745-1753.

26 Schütte H, Lohmeyer J, Rosseau S, et al. Bronchoalveolar and systemic cytokine profiles in patients with ARDS, severe pneumonia and cardiogenic pulmonary oedema. Eur Respir J 1996; 9: 1858-1867.

27 Fernández-Serrano S, Dorca J, Coromines M, Carratalà J, Gudiol F, Manresa F. Molecular inflammatory responses measured in blood of patients with severe communityacquired pneumonia. Clin Diagn Lab Immunol 2003; 10:813-820.

28 Ioanas M, Ferrer M, Cavalcanti M, et al. Causes and predictors of non-response to treatment of the ICUacquired pneumonia. Crit Care Med 2004; 32: 938-945.

29 Sibila O, Agustí C, Torres A, et al. Experimental Pseudomonas aeruginosa pneumonia: evaluation of the associated inflammatory response. Eur Respir J 2007; 30: 1167-1172.

30 Sibila O, Martinez-Olondris P, Agustí C, et al. An experimental model of pneumonia induced by MRSA in ventilated piglets. Program and abstracts of ATS 2008. International Conference of the American Thoracic Society. Am J Respir Crit Care Med 2007; 175: A327.

31 Sibila O, Luna CM, Agustí C, et al. Effects of glucocorticoids in ventilated piglets with severe pneumonia. Eur Respir J 2008; 32: 1037-1046.

32 Garraffo R, Drugeon HB, Dellamonica P, Bernard E, Lapalus P. Determination of optimal dosage regimen for amikacin in healthy volunteers by study of pharmacokinetics and bactericidal activity. Antimicrob Agents Chemother 1990; 34: 614-621. 
33 Moore RD, Smith CR, Lietman PS. Association of aminoglycoside plasma levels with therapeutic outcome in gramnegative pneumonia. Am J Med 1984; 77: 657-662.

34 Schentag JJ. Correlation of pharmacokinetic parameters to efficacy of antibiotics: relationships between serum concentrations, MIC values, and bacterial eradication in patients with gram-negative pneumonia. Scand J Infect Dis Suppl 1990; 74: 218-234.

35 Dull WL, Alexander MR, Kasik JE. Bronchial secretion levels of amikacin. Antimicrob Agents Chemother 1979; 16: 767-771.

36 Even P, Bergogne-Berezin E, Reynaud P, Berthelot G. [Pharmacokinetics of amikacin in bronchial secretions]. Nouv Presse Med 1979; 8: 3441-3444.
37 Mendelman PM, Smith AL, Levy J, Weber A, Ramsey B, Davis RL. Aminoglycoside penetration, inactivation, and efficacy in cystic fibrosis sputum. Am Rev Respir Dis 1985; 132: 761-765.

38 Pennington JE. Penetration of antibiotics into respiratory secretions. Rev Infect Dis 1981; 3: 67-73.

39 Saux MC, Crockett R, Fourtillan JB, Leng B, Couraud L. Diffusion of amikacin in the lungs. Pathol Biol (Paris) 1986; 34: 113-117.

40 Tonnellier M, Ferrari F, Goldstein I, Sartorius A, Marquette $\mathrm{CH}$, Rouby JJ. Intravenous versus nebulized ceftazidime in ventilated piglets with and without experimental bronchopneumonia: comparative effects of helium and nitrogen. Anesthesiology 2005; 102: 995-1000. 